\title{
Factors associated with the route of birth delivery in a city in the Northeast region in the State of Rio Grande do Sul, Brazil
}

Silvane Rasador 1

https://orcid.org/0000-0002-1118-3469

Claides Abegg 2

https://orcid.org/0000-0002-3808-2959

${ }_{1}^{1}$ Programa de Pós-Graduação em Saúde Coletiva. Faculdade de Enfermagem. Universidade Federal do Rio Grande do Sul. Rua São Manoel, 963. Rio Branco. Porto Alegre, RS, Brasil. CEP: 90.040-060. E-mail: srasador@yahoo.com.br.

2 Programa de Pós-Graduação em Odontologia e Saúde Coletiva. Universidade Federal do Rio Grande do Sul. Porto Alegre, RS, Brasil.

\begin{abstract}
Objectives: to investigate factors associated with the route of birth delivery in a hospital extending public and private healthcare services, in the Northeast region in the State of Rio Grande do Sul.

Methods: a cross-sectional study with 676 postpartum women, conducted from January to May 2017. The data were collected from the hospital records and women were interviewed shortly after childbirth in the maternity. Data analysis was performed by associating the Pearson's chi-square and the Poisson regression tests with robust variance.

Results: the prevalence of cesarean sections was $58.7 \%$, that is, $41.7 \%$ in public healthcare and $83.9 \%$ in private healthcare. The main reason for having a cesarean section was having had a previous one $(P R=5.69 ; C 195 \%=3.64-8.90 ; p<0.001)$, followed by having source of childbirth financing $(P R=1.54 ; C 195 \%=1.27-1.87 ; p<0.001)$, having source of prenatal care financing $(P R=1.48 ; C 195 \%=1.22-1.79 ; p<0.001)$, the childbirth and prenatal care professional $(P R=1.46 ; C 195 \%=1.28-1.66 ; p<0.001)$ and the prenatal care professional $(P R=1.43 ; C 195 \%=1.07-1.90 ; p=0.016)$.

Conclusions: the high cesarean section rates identified in this study were mainly associated with previous cesarean section. The findings suggest a change in the current childbirth care model in the city, characterized as highly medicalized, focused on the physician and on hospital care.

Key words Childbirth, Cesarean section, Risk factors, Healthcare financing
\end{abstract}

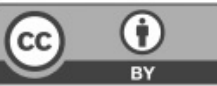




\section{Introduction}

As far as the nineteenth century, pregnant women care was performed by midwives, women who learned in practice of childbirth, which occurred in a home environment. ${ }^{1}$ As of the twentieth century, childbirth became a medical event and it started to take place inside a hospital environment. ${ }^{2}$ The institutionalization of childbirth and specially the fact that the childbirth is seen as a medical event added to a reduction of vaginal birth and increased cesarean section. ${ }^{3}$

These changes in childbirth care led, in the past few years, several countries to discuss their childbirth care model due to the increasing rates of cesarean sections. Brazil also presented an inversion in childbirth standard, as cesarean section became the most common childbirth method, reaching the total of $56.7 \%$ of all childbirths, of which, $85 \%$ took place in private healthcare services and $40 \%$ in the public healthcare. 4

World Health Organization (WHO) statement highlighted that, at population level, cesarean rates above $10 \%$ are not associated to a reduction of maternal, perinatal and neonatal death and that cesarean sections are efficient to save the life of women and babies when recommended by medical reasons. Furthermore, there are still lack of evidences to prove the benefits of cesarean sections in women and babies who do not need this surgery. 5

The research "Nascer no Brasil" (Born in Brazil), carried out by Fundação Oswaldo Cruz, was the first research to offer a national overview on the situation of childbirth care in the country and found a total of $51.9 \%$ of cesarean sections performed, reaching $89.9 \%$ in the private sector. 6 In the state of Rio Grande do Sul, according to Sistema de Informações sobre Nascidos Vivos (Sinasc) data, (Information System on Livebirths) in 2015, of all 148,359 childbirths, $61 \%$ were cesarean section. ${ }^{7}$

Among the determining factors when choosing a route of birth delivery there are traditional medical indications, preexisting clinical complications, clinical conditions that may appear during the pregnancy, the population profile and also socioeconomic and cultural conditions. ${ }^{8}$ Moreover, the current organization in obstetrician care also plays an important role in the high rates of cesarean section. 9

Regarding these indicators and taking into consideration that several studies have been pointing out the associations between high rates of cesarean sections and maternal and neonatal morbimortality, the present study aims to investigate which factors are associated with the route of birth delivery in a public and private maternity in the state of Rio Grande do Sul. The identification of these factors will allow to develop strategies to improve the childbirth care in that city.

\section{Methods}

A cross-sectional design was carried out in a public and private service hospital, referred for performing childbirths in the city of Bento Gonçalves and surrounding region in the state of Rio Grande do Sul. In this study, all women who had recently given birth to live births in the period of January to May 2017 were included. Foreigners who could not understand Portuguese and women who gave birth to stillbirth were considered as exclusion criteria.

The information was collected by two researchers through hospital records analysis and interviewing women during the hospitalization period, respecting the minimum period of 12 hours after childbirth. Childbirth data was collected in the hospital records, as well as the physician's recommendation for a cesarean section. For the interview, a form based on the research "Nascer no Brasil: Inquérito Nacional sobre Parto e Nascimento" (Born in Brazil: A National Survey on Childbirth) was used. 10

As dependent variable (outcome), the type of childbirth categorized as vaginal birth or cesarean was considered. The reference category was vaginal birth. The investigated factors such as independent variables were divided into three groups: 1 : sociodemographic data: age (below or equal to 25 years old, between 26 and 34 years old, 35 years old or more); schooling level (elementary, high school, higher education); self-declared skin color (white, not white); marital status (living with a partner, living without a partner); paid occupation (yes, no); family income (up to 2 minimum salaries, between 2 and 4 minimum salaries, above 4 minimum salaries). 2 : obstetric and prenatal care data: planned pregnancy (yes, no); parity (primiparous women, multiparous women); previous cesarean section in multiparous women (yes, no); prenatal performance (yes, no); prenatal financing source (public, private); professional who performed the prenatal (physician, physician and nurse); number of prenatal consultations (between 1 and 5, 6 or above); risky pregnancy (yes, no); presence of hypertensive diseases in current pregnancy (yes, no); presence of diabetes in current pregnancy (yes, no); type of childbirth preferred at the beginning of pregnancy (vaginal, cesarean, no preference). 3: data regarding to childbirth: child- 
birth financing source (public, private); prenatal and childbirth professional (the same, different).

The data analysis was performed using the Statistical Package for the Social Sciences program - SPSS for Windows, 18.0 version and initially it included the distribution of the frequency of the variables studied and the performance of the association test by Pearson's chi-square. Then, the prevalence ratio by Poisson regression with robust univariate and multivariate variance was calculated. The criteria for the variable entry in the multivariate model was that it showed the same value of $p<0.20$ in the univariate analysis. The significance level adopted was of $5 \%$. The variables which were associated with the outcome were kept in the final model $(p \leq 0.05 \%)$.

The study was approved by the Comitê de Ética em Pesquisa (CEP) (Research Ethics Committee), at the Universidade Federal do Rio Grande do Sul and by the CEP of the co-participating hospital (CAAE number 62469416.9.0000.5347, under the document number 1.845.180).

\section{Results}

The final sample size were 676 postpartum women (Table 1), with loss percentage of $4.1 \%$. In the study two home childbirths and out of hospital patients was included because after the childbirth both mother and baby were immediately taken to the maternity. There were 13 losses due to hospital leave prior to the interview (1.85\%) and only six postpartum women refused to participate in the study $(0.85 \%)$. Three foreign women were excluded because they did not understand Portuguese. Six women whose childbirth resulted in stillborn and one postpartum woman gave her child up for adoption after birth (1\%).

The women interviewed were in average 28 years old $(\mathrm{DP}=6.25)$, ranging from 16 to 45 years old. Most of the investigated population selfdeclared as their skin color being white $(68.5 \%)$, presented to have concluded high school level $(46.7 \%)$, lived with a partner $(91 \%)$, had a paying job $(69.2 \%)$ with gross family income of maximum two minimum salaries (44.9\%); $55.1 \%$ of the women reported that they had planned their current pregnancy; a little over half (55\%), were primiparous women and 304 were multiparous women (45\%), among these, $57.6 \%$ had at least one previous cesarean section.

In relation to prenatal, $55.6 \%$ had medical consultations using the public healthcare, and the rest of them used either private healthcare or private healthcare insurance plans (44.4\%). Only three women stated that they did not have prenatal care $(0.4 \%)$, while the majority of the women had at least six consultations $(91.7 \%)$, as it is proposed by the Ministério da Saúde (MS) (Brazilian Health Ministry). Physicians were responsible for $86.6 \%$ of the prenatal consultations while the others were assisted by a physician and a nurse together to have their prenatal consultation.

Approximately $23 \%$ of the postpartum women reported having risk pregnancy or were taken to a high-risk pregnancy hospital service. The prevalence of hypertensive diseases and diabetes in the current pregnancy was of $9.9 \%$ and $5.8 \%$, respectively.

In the beginning of the pregnancy, the preferred route of birth delivery was vaginal for $66.3 \%$ of the women. It was found that $37.4 \%$ of the women were assisted by the same professional during prenatal and childbirth. Regarding to childbirth financing source, 403 (59.6\%) used the Sistema Único de Saúde (SUS) (Public Health System).

The prevalence of cesarean section was of $58.7 \%$, reaching $83.9 \%$ in the private sector. In the public sector, $58.3 \%$ of the women had vaginal birth although the number of cesarean section was also significant (41.7\%). (Table 1).

In the univariate analysis, an association was observed between the outcome with the following variables: mother's age was higher; higher schooling level; paid job; high income; planned pregnancy; previous cesarean section; private financing for prenatal; prenatal was performed by an only physician; the same professional performed both prenatal and childbirth; hypertensive disease development in the current pregnancy; desire for cesarean section or not having a well-defined preference for the type of childbirth at the beginning of the pregnancy and private financing for childbirth. (Table 2).

After the adjustments in the complete model, including the variables that showed a value of $p<0.20$ in the univariate analysis, it was found that, the higher the school level, the higher the prevalence on cesarean section. Women with higher education showed $33 \%$ of cesarean section prevalence, when compared to the ones who had only elementary schooling level $(\mathrm{PR}=1.33 ; \quad \mathrm{CI} 95 \%=1.07-1.65$; $p=0.010$ ).

Regarding the mother's age, even though we did not find any significant association, it is relevant to point out that cesarean section incidence increased from $44.1 \%$ in women under 25 years old to $75.4 \%$ in women above 35 years of age.

Among the multiparous women who underwent previous cesarean section, the prevalence of 
Table 1

Frequency of the type of childbirth, according to sociodemographic and obstetric prenatal variables and related to childbirth at a mixed service hospital, RS, January-May 2017.

\begin{tabular}{|c|c|c|c|c|c|c|}
\hline \multirow{3}{*}{$\begin{array}{l}\text { Variables } \\
\text { Route of birth delivery }\end{array}$} & \multirow{3}{*}{$\begin{array}{c}\mathbf{N} \\
676\end{array}$} & \multirow{3}{*}{$\begin{array}{c}\% \\
100.0\end{array}$} & \multicolumn{4}{|c|}{ Prevalence } \\
\hline & & & \multicolumn{2}{|c|}{ Vaginal } & \multicolumn{2}{|c|}{ Cesarean } \\
\hline & & & 279 & 41.3 & 397 & 58.7 \\
\hline \multicolumn{7}{|l|}{ Age (years) } \\
\hline$\leq 25$ & 254 & 37.6 & 142 & 55.9 & 112 & 44.1 \\
\hline $26-34$ & 300 & 44.4 & 107 & 35.7 & 193 & 64.3 \\
\hline$\geq 35$ & 122 & 18.0 & 30 & 24.3 & 92 & 75.4 \\
\hline \multicolumn{7}{|l|}{ Schooling level } \\
\hline Elementary & 155 & 23.0 & 91 & 58.7 & 64 & 41.3 \\
\hline High School & 316 & 46.7 & 132 & 41.8 & 184 & 58.2 \\
\hline Higher Education & 205 & 30.3 & 56 & 27.3 & 149 & 72.7 \\
\hline White skin & 463 & 68.5 & 182 & 39.3 & 281 & 60.7 \\
\hline With partner & 615 & 91.0 & 245 & 39.8 & 370 & 60.2 \\
\hline Paid Job & 468 & 69.2 & 166 & 35.5 & 302 & 64.5 \\
\hline \multicolumn{7}{|l|}{ Family income* (minimum salary) } \\
\hline Up to 2 & 302 & 44.9 & 156 & 51.7 & 146 & 48.3 \\
\hline Between 2 and 4 & 260 & 38.7 & 95 & 36.5 & 165 & 63.5 \\
\hline Above 4 & 110 & 16.4 & 5 & 22.7 & 85 & 77.3 \\
\hline Planned pregnancy & 372 & 55.1 & 123 & 33.1 & 249 & 66.9 \\
\hline Primiparous women & 372 & 55.1 & 141 & 37.9 & 231 & 62.1 \\
\hline Previous cesarean section & 175 & 57.6 & 27 & 15.4 & 148 & 84.6 \\
\hline Prenatal care performance & 673 & 99.6 & 0 & - & 0 & - \\
\hline \multicolumn{7}{|l|}{ Prenatal care financing } \\
\hline Public & 374 & 55.6 & 221 & 59.1 & 153 & 40.9 \\
\hline Private & 299 & 44.4 & 56 & 18.7 & 243 & 81.3 \\
\hline \multicolumn{7}{|l|}{ Prenatal care } \\
\hline Physician & 583 & 86.6 & 217 & 37.2 & 366 & 62.8 \\
\hline Physician and nurse & 90 & 13.4 & 60 & 66.7 & 30 & 33.3 \\
\hline Six or more prenatal consultations & 617 & 91.7 & 250 & 40.5 & 367 & 59.5 \\
\hline Risk pregnancy & 155 & 22.9 & 59 & 38.1 & 96 & 61.9 \\
\hline \multicolumn{7}{|l|}{ Hypertension/preeclampsia/eclampsia } \\
\hline in current pregnancy & 67 & 9.9 & 14 & 20.9 & 53 & 79.1 \\
\hline Diabetes in current pregnancy & 39 & 5.8 & 12 & 30.3 & 27 & 69.2 \\
\hline \multicolumn{7}{|c|}{$\begin{array}{l}\text { Desired type of childbirth at the beginning of } \\
\text { the pregnancy }\end{array}$} \\
\hline Vaginal birth & 448 & 66.3 & 232 & 51.8 & 216 & 48.2 \\
\hline Cesarean section & 160 & 23.7 & 25 & 15.6 & 135 & 84.4 \\
\hline No preference & 68 & 10.1 & 22 & 32.4 & 46 & 67.6 \\
\hline \multicolumn{7}{|l|}{ Prenatal and childbirth professional } \\
\hline The same & 252 & 37.4 & 41 & 16.3 & 211 & 83.7 \\
\hline Different & 421 & 62.6 & 236 & 56.1 & 185 & 43.9 \\
\hline \multicolumn{7}{|l|}{ Childbirth financing } \\
\hline Public & 403 & 59.6 & 235 & 58.3 & 168 & 41.7 \\
\hline Private & 273 & 40.4 & 44 & 16.1 & 229 & 83.9 \\
\hline
\end{tabular}

*Considering the value of the minimum salary in the year of $2017-\mathrm{R} \$ 937.00$.

RS-Rio Grande do Sul State. 
Table 2

Robust Poisson Regression of the variables associated with the type of childbirth in a hospital with mixed healthcare service. RS, January-May 2017.

\begin{tabular}{|c|c|c|c|c|}
\hline Variables & PR (Cl95\%) & $p$ & $\mathrm{PR}_{\mathrm{adj}}(\mathrm{Cl} 95 \%)$ & $p$ \\
\hline \multicolumn{5}{|l|}{ Age (years) } \\
\hline$\leq 25$ & 1.00 & & 1.00 & \\
\hline $26-34$ & $1.46(1.24-1.72)$ & $<0.001$ & $1.03(0.88-1.21)$ & 0.746 \\
\hline$\geq 35$ & $1.71(1.44-2.03)$ & $<0.001$ & $1.04(0.87-1.25)$ & 0.668 \\
\hline \multicolumn{5}{|l|}{ Schooling level } \\
\hline Elementary & 1.00 & & 1.00 & \\
\hline High school & $1.41(1.14-1.74)$ & $<0.001$ & $1.26(1,03-1.53)$ & 0.022 \\
\hline Higher education & $1.76(1.43-2.16)$ & $<0.001$ & $1.33(1,07-1.65)$ & 0.010 \\
\hline White skin & $1.11(0.96-1.28)$ & 0.138 & $0.93(0,82-1.07)$ & 0.308 \\
\hline With partner & $1.35(1.01-1.81)$ & 0.037 & $1.11(0,84-1.47)$ & 0.460 \\
\hline Paid job & $1.41(1.20-1.66)$ & $<0.001$ & $1.03(0.88-1.20)$ & 0.725 \\
\hline \multicolumn{5}{|l|}{ Family income (minimum salary) } \\
\hline Up to 2 & 1.00 & & 1.00 & \\
\hline Between 2 and 4 & $1.31(1.13-1.52)$ & $<0.001$ & $1.03(0.89-1.19)$ & 0.694 \\
\hline Above 4 & $1.59(1.37-1.86)$ & $<0.001$ & $1.09(0.92-1.30)$ & 0.305 \\
\hline Planned pregnancy & $1.37(1.19-1.56)$ & $<0.001$ & $1.05(0.92-1.21)$ & 0.484 \\
\hline Primiparous women & $1.13(0.99-1.29)$ & 0.052 & $1.11(0.98-1.25)$ & 0.114 \\
\hline Previous cesarean & $6.06(3.93-9.34)$ & $<0.001$ & $5.69(3.64-8.90)$ & $<0.001$ \\
\hline \multicolumn{5}{|l|}{ Prenatal care financing } \\
\hline Public & 1.00 & & 1.00 & \\
\hline Private & $1.98(1.73-2.27)$ & $<0.001$ & $1.48(1.22-1.79)$ & $<0.001$ \\
\hline \multicolumn{5}{|l|}{ Prenatal care professional } \\
\hline Physician & $1.88(1.39-2.53)$ & $<0.001$ & $1.43(1.07-1.90)$ & 0.016 \\
\hline Physician and nurse & 1.00 & & 1.00 & \\
\hline Six or more prenatal care consultations & $1.14(0.88-1.49)$ & 0.298 & - & - \\
\hline Risk pregnancy & $1.07(0.92-1.23)$ & 0.342 & - & - \\
\hline \multicolumn{5}{|l|}{ Hypertension/preeclampsia/eclampsia } \\
\hline in current pregnancy & $1.39(1.21-1.61)$ & $<0.001$ & $1.45(1.25-1.66)$ & $<0.001$ \\
\hline Diabetes in current pregnancy & $1.19(0.95-1.48)$ & 0.120 & $1.06(0.86-1.31)$ & 0.574 \\
\hline \multicolumn{5}{|l|}{ Desired type of childbirth at the } \\
\hline \multicolumn{5}{|l|}{ beginning of the pregnancy } \\
\hline Vaginal birth & 1.00 & & 1.00 & \\
\hline Cesarean section & $1.75(1.55-1.96)$ & $<0.001$ & $1.27(1.13-1.42)$ & $<0.001$ \\
\hline No preference & $1.40(1.16-1.69)$ & $<0.001$ & $1.21(1.02-1.43)$ & 0.031 \\
\hline \multicolumn{5}{|l|}{ Prenatal care and childbirth professional } \\
\hline The same & $1.90(1.68-2.15)$ & $<0.001$ & $1.46(1.28-1.66)$ & $<0.001$ \\
\hline Different & 1.00 & & 1.00 & \\
\hline \multicolumn{5}{|l|}{ Childbirth financing } \\
\hline Public & 1.00 & & 1.00 & \\
\hline Private & $2.01(1.77-2.28)$ & $<0.001$ & $1.54(1.27-1.87)$ & $<0.001$ \\
\hline
\end{tabular}

$\mathrm{PR}=$ Prevalence Ratio; $\mathrm{PR}_{\mathrm{adj}}=$ Adjusted prevalence ratio.

RS - Rio Grande do Sul State. 
cesarean section was almost six times higher than the ones who had previous vaginal birth $(\mathrm{PR}=5.69$; CI95\%=3.64-8.90; $p<0.001$ ).

When evaluating the type of childbirth in accordance with the prenatal financing, we found a cesarean section prevalence of $48 \%$ in women who performed their prenatal using the private healthcare service, when compared to those who performed at the public healthcare service $(\mathrm{PR}=1.48$; CI95\%=1.22-1.79; $p<0.001)$.

When prenatal care was performed by only a physician, there was a higher prevalence of $43 \%$ of cesarean section than when prenatal care performed by both the physician and nurse $(\mathrm{PR}=1.43$; CI95\%=1.07-1.90; $p=0.016$ ).

An important difference was also found concerning the professional who performed the prenatal care and the childbirth. When the professional physician accompanied the childbirth was the same who performed the prenatal care, in which we found $46 \%$ of the prevalence of cesarean section in comparison to those women assisted by different professionals in the prenatal care and in childbirth $(\mathrm{PR}=1.46$; $\mathrm{CI} 95 \%=1.28-1.66 ; p<0.001)$.

The presence of hypertensive disease (hypertension, preeclampsia and eclampsia) during pregnancy, showed a prevalence of cesarean section of $45 \%$ $(\mathrm{PR}=1.45 ; \mathrm{CI} 95 \%=1.25-1.66 ; p<0.001)$.

When analyzing the desired type of childbirth at the beginning of the pregnancy, it was found that there is a prevalence of cesarean section of $27 \%$ in women who already had an initial preference for cesarean section in comparison to those who initially preferred vaginal birth $(\mathrm{PR}=1.27$; CI95\%=1.13-1.42; $p<0.001)$. The same group of women who did not show a well-defined initial preference, showed a prevalence of cesarean section of $21 \%$ in relation to those who preferred vaginal birth $(\mathrm{PR}=1.21$; CI95\%=1.02-1.43; $p=0.031$ ).

The prevalence of cesarean section was observed in $54 \%$ in women who underwent childbirth in the private healthcare service in comparison to those who were assisted in the public healthcare service $(\mathrm{PR}=1.54 ; \mathrm{CI} 95 \%=1.27-1.87 ; p<0.001)$.

\section{Discussion}

We identified high cesarean section rates which were associated with previous cesarean section, childbirth and private financing for prenatal care; the same professional who performed both the prenatal care and childbirth; performed prenatal care only.

The prevalence cesarean section found, $58.7 \%$, is similar to what Rattner and Moura11 described in the South region of Brazil. There was a higher number of cesarean sections in the private healthcare service when in comparison to the public healthcare service, such findings were also reported in a recent Brazilian study. 6

The strongest variable associated with the outcome was the previous cesarean section, which presented a prevalence almost six times higher than the incidence of new cesarean section, when compared to the multiparous women whose previous childbirths were vaginal birth.

This result was also found in studies conducted in the state of Florianópolis/SC ${ }^{9}$ and in the city of Maringá/PR. 12 The high number of cesarean sections found in this study on primiparous women is worrisome $(62.1 \%)$, as it has already been reported in other studies, 13,14 because it shows a tendency for choosing cesarean sections in future pregnancies. Patel and Jain 15 concluded that there are very few risks in vaginal birth after previous cesarean section, although, serious adverse outcomes may occur if there is a uterine rupture. Avoiding such risk could one possible reason to why new cesarean section is often chosen. Whilst repeated cesarean section risks are very frequent, however are less serious.

It was found that the performance of prenatal care in the private healthcare is associated to the highest cesarean section performed. Similar result was found in the city of Tubarão/SC, where the performance of prenatal care in the private healthcare increased by over $80 \%$ the probability of performing a cesarean section. 16 Alike, a study in Botucatu/SP, found an association between elective cesarean section and the performance of a prenatal care in the complementary health network. 17 These findings may a suggest an influence of the health professionals from the private healthcare who might frequently recommend this type of childbirth.

The prenatal care performed by a physician only also shows association with the higher prevalence of cesarean sections. The Ministério da Saude (Brazilian Health Ministry) recommends that the prenatal consultations should alternate physicians and nurses. ${ }^{18}$ Nursing professionals have legal and ethical support to perform low risk prenatal care providing real benefits to the patients. ${ }^{1}$ Nonetheless, prenatal care performed by nurses is still restricted in this country, and it is more common in the North and Northeast region of Brazil. ${ }^{19}$ In comparison to prenatal care performance models, a recent systematic review concluded that the model in which pregnant women received continuous obstetric care led by midwives showed less probability of interventions and higher probability of satisfaction with the 
offered care. Whereas both care models, led by obstetricians and led by physicians, showed equal probability of childbirth as cesarean section. ${ }^{20}$

The patients who were assisted by complementary health network or the ones who take total charge of the health expenses are usually assisted by the same physician in both prenatal care and childbirth. ${ }^{21}$ Such fact has been creating opportunity for physician-patient bonding, facilitating the planning and performance of cesarean section, which would explain the high incidence of the type of childbirth when the professional who performed the childbirth was the same who performed the prenatal care. Similarly, a study conducted in a private maternity hospital in Ribeirão Preto/SP, has already described this close relationship between obstetrician and patient in the private healthcare. 22 Under these circumstances, the same physician accompanies the patient in the prenatal care and in childbirth, which enables this professional to turn the type of childbirth into a consumer good, which is viable according to the patient's financial conditions.

Several studies have found high probability of cesarean section performed in women with hypertensive diseases in the current pregnancy, just as highlighted in this very research.12,22-25 However, low prevalence of these pathologies in this study does not explain the high rate of cesarean section found.

The desire for a cesarean section at the beginning of the pregnancy or not having an initial type of childbirth preference showed association with high performance of cesarean section. This has been one of the explanations for high rates of cesarean sections found throughout the world. However, despite recent research showed evidence of the increased desire for cesarean section in Brazil, when compared to previous studies, women still preferred vaginal birth at the beginning of the pregnancy. ${ }^{13} \mathrm{~A}$ study which included the analysis of 38 articles, found that only a minority of women, $15.6 \%$, in several countries expressed preference for cesarean section. Those who did preferred cesarean sections mostly had already had a previous cesarean section or lived in countries of average income. ${ }^{26}$

A strong association was found between cesarean section and private financing source for childbirth, the prevalence of being $54 \%$. Such findings support what has already been found in the literature, that cesarean section were almost double in private maternity hospitals when compared to SUS, 14,16 and non-SUS cesarean section rates were more frequent than SUS cesarean sections. 27 In private healthcare the pregnant women can choose the physician who will perform the prenatal care and childbirth and it is possible to schedule a cesarean section, according to the woman's desire and/or the obstetrician's recommendation. Such way the private healthcare may justify the high rate of cesarean section in complementary healthcare network. ${ }^{13}$

In this study, the variables strongly associated with the increase of the prevalence of cesarean section which had more relation to obstetric factors, prenatal care and childbirth in detriment of sociodemographic factors. The only sociodemographic variable associated to the incidence of cesarean section was the schooling level. Such result is considered consensus in the literature. 11,25,28,29

However, the associations found such as in private financing source for prenatal care, private childbirth, the same professional who performed both the prenatal care and childbirth and the women's schooling level, suggest what several studied have been pointing out, showing that rates of cesarean section in Brazil are higher in the population groups which have better financial conditions. 25 It should be also noted that the city in which that study was conducted has a Human Development Index which is considered high (0.778). 30

According to WHO, 5 the effects of high rates of cesarean sections are yet unclear when it comes to other outcomes apart from mortality, such as perinatal and mother's morbidity, pediatric outcomes and social or psychological wellbeing. More studies are necessary in order to understand which are the immediate and long-term effects of cesarean section in health.

The major finding of this study is that the prevalence of the cesarean section was almost six times higher in pregnant women who had previous cesarean section which is the main risk factor for performing a new cesarean section followed by childbirth and private financing for prenatal care.

The strong association found between previous cesarean section and the performance of cesarean section brings us to what several studies have already found regarding the importance of preventing cesarean section among primiparous women, because such factor can influence in future pregnancies enhancing rates of childbirth operations. The usage of Planos de Parto (Childbirth Planning) as a tool to stimulate women to reflect upon their desired childbirth as well as, the discussion about the recommendation of a surgical childbirth if necessary, considering that this device influences positively in the childbirth process reinforcing women's autonomy and increasing their satisfaction.

Action are recommended in the complementary healthcare with a view to reduce high rates of 
surgical childbirths present in this sector. It is important to take into consideration the insertion of other professionals in direct assistance for low risk childbirth, such as obstetric nurses or midwives and doulas, as it already occurs in other countries, for instance Holland, where there is smaller medical intervention and more participation of other professionals within obstetric assistance, has produced positive results.

\section{References}

1. Garcia SAL, Garcia SAL, Lippi UG. A necessidade de inserção do enfermeiro obstetra na realização de consultas de pré-natal na rede pública. Einstein. 2010; 8(2) (parte 1): 241-7.

2. Nagahama EEI, Santiago SM. A institucionalização médica do parto no Brasil. Ciênc Saúde Colet. 2005; 10(3): 651-7.

3. Carneiro LMA, Paixão GPN, Sena CD, Souza AR, Silva RS, Pereira A. Parto natural X parto cirúrgico: percepções de mulheres que vivenciaram os dois momentos. Rev Enfer Cent O Min. 2015; 5 (2): 1574-85.

4. BRASIL. Ministério da Saúde. Secretaria de Ciência, Tecnologia e Insumos Estratégicos. Diretrizes de atenção à gestante: a operação cesariana. Brasília (DF), 2016.

5. WHO (World Health Organization). Statement on caesarean section rates. Geneva: WHO. 2015 [acesso em 2017 jun 20]. Disponível em: http://apps.who.int/iris/bitstream/ 10665/161442/1/WHO_RHR_15.02_eng.pdf.

6. Leal MC, Pereira APE, Domingues RMSD, Theme Filha MM, Dias MAB, Nakamura-Pereira M, Bastos MH, Gama SGN. Intervenções obstétricas durante o trabalho de parto e parto em mulheres brasileiras de risco habitual. Cad Saúde Pública. 2014; 30: 17-47.

7. Brasil. Ministério da Saúde. DATASUS. Sistema de Informações sobre Nascidos Vivos [Internet]. 2015 [acesso em 2016 jun 13]. Disponível em: http://tabnet.datasus.gov.br/cgi/deftohtm.exe?sinasc/cnv/nv uf.def.

8. Accetta SG. Fatores de risco clínicos, obstétricos e demográficos relacionados à indicação de cesarianas em nulíparas em um hospital universitário: estudo de coorte prospectivo [tese]. Porto Alegre: Universidade Federal do Rio Grande do Sul - UFRGS; 2011.

9. Sakae TM, Freitas PF, D’Orsi E. Fatores associados a taxas de cesárea em hospital universitário. Rev Saúde Pública. 2009; 43 (3): 472-80.

10. Leal MC, Silva AAM, Dias MA, Gama SGN, Rattner D, Moreira ME, Theme Filha MM, Domingues RMSM, Pereira APE, Torres JA, Bittencourt DAS, D’Orsi E, Cunha AJLA, Leite AJM, Cavalcante RS, Lansky S, Diniz CSG, Szwarcwald CL. Birth in Brazil: national survey into labour and birth. Reprod Health. 2012; 9 (1): 15.

11. Rattner D, Moura EC. Nascimentos no Brasil: associação do tipo de parto com variáveis temporais e sociodemográficas. Rev Bras Saúde Mater Infant. 2016; 16 (1): 39-47.

\section{Authors' contribution}

Rasador S and Abegg C participated in the conception of the research, analysis and interpretation of the data as well as the manuscript writing. Data collection was conducted by Rasador S only. Both authors read and approved the final version of the manuscript.
12. Oliveira RR, Melo EC, Novaes ES, Ferracioli PLRV, Mathias TAF. Factors associated to caesarean delivery in public and private health care systems. Rev Esc Enferm USP. 2016; 50 (5): 733-40.

13. Domingues RMSM, Dias MAB, Nakamura-Pereira M, Torres JA, d'Orsi E, Pereira APE, Schilithz AOC, Leal MC. Processo de decisão pelo tipo de parto no Brasil: da preferência inicial das mulheres à via de parto final. Cad Saúde Pública. 2014; 30 (Suppl. 1): S101-16.

14. Freitas PF, Fernandes TMB. Associação entre fatores institucionais, perfil da assistência ao parto e as taxas de cesariana em Santa Catarina. Rev Bras Epidemiol. 2016; 19 (3): 525-38.

15. Patel RM, Jain L. Delivery after previous cesarean: shortterm perinatal outcomes. Semin Perinatol. 2010; 34 (4): $272-80$.

16. Freitas PF, Savi EP. Social inequalities in post-cesarean complication rates: a hierarchical analysis. Cad Saúde Pública. 2011; 27 (10): 2009-20.

17. Ferrari AP, Carvalhaes MAB, Parada CMGL. Associação entre pré-natal e parto na rede de saúde suplementar e cesárea eletiva. Rev Bras Epidemiol. 2016; 19(1): 75-88.

18. Brasil. Ministério da Saúde. Secretaria de Atenção à Saúde. Departamento de Atenção Básica. Atenção ao pré-natal de baixo risco [Internet]. 1 ed. rev. Brasília, DF; 2013. 318p. (Cadernos de Atenção Básica, nº 32).

19. Viellas EF, Domingues RMSM, Dias MAB, Gama SGN, Theme Filha MM, Costa JV, Bastos MH, Leal MC. Assistência pré-natal no Brasil. Cad Saúde Pública. 2014; 30 (Supl.): S85-S100.

20. Sandall J. Midwife-led continuity models versus other models of care for childbearing women. Cochrane Database Syst Rev. 2016; 4: CD004667.

21. Patah LEM, Malik AM. Modelos de assistência ao parto e taxa de cesárea em diferentes países. Rev Saúde Pública. 2011; 45 (1): 185-94.

22. Almeida S, Bettiol H, Barbieri MA, Silva AAM, Ribeiro VS. Significant differences in cesarean section rates between a private and a public hospital in Brazil. Cad Saúde Pública. 2008; 24 (12): 2909-18.

23. Silveira DS, Santos IS. Fatores associados à cesariana entre mulheres de baixa renda em Pelotas, Rio Grande do Sul, Brasil. Cad Saúde Pública. 2004; 20: 231-41. 
24. Villar J, Valladares E, Wojdyla D, Zavaleta N, Carroli G, Velazco A, Shah A, Campodónico L, Bataglia V, Faundes A, Langer A, Narváez A, Donner A, Romero M, Reynoso S, Pádua KS, Giordano D, Kublickas M, Acosta A. Caesarean delivery rates and pregnancy outcomes: the 2005 WHO global survey on maternal and perinatal health in Latin America. Lancet. 2006; 367 (9525): 1819-29.

25. Pádua KS, Osis MJD, Faúndes A, Barbosa AH, Moraes Filho OB. Fatores associados à realização de cesariana em hospitais brasileiros. Rev Saúde Pública. 2010: 44 (1): 709.

26. Mazzoni A, Althabe L, Liu NH, Bonotti AM, Gibbons L, Sánchez AJ, Belizán JM. Women's preference for caesarean section: a systematic review and meta-analysis of observational studies. BJOG. 2011; 118: 391-9.

27. Paris GF, Monteschio LVC, Oliveira RR, Latorre MRDO, Pelloso SM, Mathias TAF. Tendência temporal da via de parto de acordo com a fonte de financiamento. Rev Bras Ginecol Obstet. 2014; 36 (12): 548-54.

Received on February 5, 2018

Final version presented on June 6, 2019

Approved on August 5, 2019
28. Freitas PF, Drachler ML, Leite JCC, Grassi PR. Desigualdade social nas taxas de cesariana em primíparas no Rio Grande do Sul. Rev Saúde Pública. 2005; 39 (5): 761-7.

29. Freitas PF, Sakae TM, Jacomino MEMLP. Fatores médicos e não-médicos associados às taxas de cesariana em um hospital universitário no Sul do Brasil. Cad Saúde Pública. 2008; 24 (5): 1051-61.

30. Nações Unidas. Programa das Nações Unidas para o Desenvolvimento. Instituto de Pesquisa Econômica Aplicada. Fundação João Pinheiro. Atlas do Desenvolvimento Humano no Brasil; 2013. Disponível em: http://atlasbrasil.org.br/2013/pt/perfil_m/bentogoncalves_rs 